\title{
Treze cartas inéditas de Mário de Andrade
}

[ Thirteen unpublished letters from Mário de Andrade

Marcos Antonio de Moraes ${ }^{\mathrm{I}}$

Rodrigo Jorge Ribeiro Neves ${ }^{2}$

MORAES, Marcos Antonio de; NEVES, Rodrigo Jorge Ribeiro. Treze cartas inéditas de Mário de Andrade. Revista do Instituto de Estudos Brasileiros, Brasil, n. 67, p. 240-242, ago. 2017.

DOI: http://dx.doi.org/IO.II606/issn.23I6-90IX.voi67p240-242

I Universidade de São Paulo (USP, São Paulo, SP, Brasil).

2 Universidade de São Paulo (USP, São Paulo, SP, Brasil). 


\section{A Antonio Candido}

Em I946, Antonio Candido divulga, na Revista do Arquivo Municipal de São Paulo, "Mário Andrade", homenagem ao escritor falecido em 25 de fevereiro de I945. O crítico literário avalia a importância das cartas do criador de Macunaíma: "a sua correspondência encherá volumes e será porventura o maior monumento do gênero em língua portuguesa: terá devotos fervorosos e apenas ela permitirá uma vista completa da sua obra e do seu espírito"3. De fato, o prognóstico vem se confirmando, tendo em vista a extensa bibliografia da produção epistolar mariodeandradiana atualmente conhecida, bem como o número expressivo de estudos críticos. Além do que se encontra esparsamente em periódicos e como matéria documental de dissertações e teses universitárias, conhecemos quase quarenta volumes de suas cartas, com perspectivas reais de ampliação, considerando as edições em preparo por diversos organizadores, muitas delas a serem difundidas proximamente na Coleção Correspondência Mário de Andrade, pela Edusp/IEB, com a participação de outras editoras. As cartas de Mário contribuem substancialmente para o desenvolvimento de muitas áreas do saber, que fazem uso da epistolografia enquanto fonte de informações. Essa rica documentação, mantida em tantos acervos públicos e privados, vem sendo coligida para compor, nos próximos anos, a publicação da Correspondência reunida de Mário de Andrade, pesquisa em processo de Marcos Antonio de Moraes, no IEB/USP.

Este número da Revista do Instituto de Estudos Brasileiros - RIEB compartilha com os leitores um conjunto de cartas inéditas do escritor, apresentadas por estudiosos no assunto. Com o intuito de padronizar a metodologia de transcrição das cartas e cumprir o objetivo de publicação de textos fidedignos, procedemos ao cotejo e estabelecimento do texto a partir dos manuscritos originais ou de fotocópias de que dispomos. Adotamos os seguintes critérios normativos, em consonância com os pressupostos editoriais da Coleção Correspondência Mário de Andrade: atualização

3 CANDIDO, Antonio. Mário de Andrade. Revista do Arquivo Municipal. São Paulo, jan.-fev. I946. Ano XII, volume CVI, p. 69. (Edição fac-similar. Revista do Arquivo Municipal. Departamento do Patrimônio Histórico, São Paulo, I98, I990). 
da ortografia conforme o Vocabulário Ortográfico da Língua Portuguesa em vigor; reconhecimento das idiossincrasias linguísticas do autor modernista (como "inda", "rúim" e "desque"); apresentação do cabeçalho da carta com lugar, dia, mês por extenso e ano completo; formatação em itálico de títulos de livros e periódicos, com exceção de substantivações de nomes próprios, como em “Klaxons”; manutenção de sublinhados, de expressões estrangeiras sem formatação e de abreviações, como em "Rev. Acadêmica"; substituição das formas "si”, "sinão", "milhor", "mamãi” pelos seus respectivos vocábulos atualizados; correção conjectural de erros de datilografia, como "linpos" e "pâdega". Mantivemos a pontuação original. Quanto aos nomes próprios, atualizamos “Mário” (nas cartas, “Mario”), "Oneyda” (“Oneida”) e “Gandhi” (“Gandi”).

Ao concretizar a publicação das treze cartas inéditas de Mário de Andrade que contribuem para o conhecimento de aspectos de sua biografia e de seus vínculos de amizade intelectual, agradecemos a Daliana Cascudo e a Camilla Cascudo, do Ludovicus - Instituto Câmara Cascudo; ao Centro Cultural Martha Watts, Universidade Metodista de Piracicaba - Unimep; à professora Alice E. D. Olivati; a Elisabete Marin Ribas, supervisora técnica do setor de Arquivo do Instituto de Estudos Brasileiros da USP, e sua equipe; e a Marco Antonio Teixeira Júnior, bolsista de iniciação científica do Programa Unificado de Bolsas, USP, no IEB.

\title{
SOBRE OS AUTORES
}

\author{
MARCOS ANTONIO DE MORAES é professor \\ de Literatura Brasileira do Instituto de Estudos \\ Brasileiros (IEB/USP) e organizador de Câmara \\ Cascudo e Mário de Andrade. Cartas, I924-I944 (2010). \\ E-mail:mamoraes@usp.br
}

RODRIGO JORGE RIBEIRO NEVES é pesquisador de pós-doutorado do IEB/USP e bolsista Fapesp, com o projeto "Edição de texto fidedigno e anotada da correspondência de Mário de Andrade e Carlos Lacerda".

E-mail: rodrigorirn@gmail.com

\section{REFERÊNCIA BIBLIOGRÁFICA}

CANDIDO, Antonio. Mário de Andrade. Revista do Arquivo Municipal. São Paulo, jan.-fev. 1946. Ano XII, volume CVI, p. 69. (Edição fac-similar. Revista do Arquivo Municipal. Departamento do Patrimônio Histórico, São Paulo, I98, I990). 